\title{
Determining the Anxiety Sensitivity Bases of Anxiety: A Study with Undergraduate Students
}

\author{
Atilgan Erozkan \\ Faculty of Education, Mugla Sitki Kocman University, Mugla, Turkey
}

Copyright $(2017$ by authors, all rights reserved. Authors agree that this article remains permanently open access under the terms of the Creative Commons Attribution License 4.0 International License

\begin{abstract}
This study aims to examine the relationships between subdimensions of anxiety sensitivity and anxiety. The participants in the study were 841undergraduate students (411 females; 430 males) randomly selected from three different faculties -Faculties of Technical Education, Education, and Sport Sciences- at Mugla Sitk1 Kocman University. Data collection instruments included the Anxiety Sensitivity Index-Revised, (ASI-R), and also Beck Anxiety Inventory, (BAI). The data were analyzed using Pearson product-moment correlation analysis and structural equation modeling. The results indicate that there were significant positive associations between subdimensions of anxiety sensitivity and anxiety. The results also indicated that the fear of cognitive dyscontrol subdimension of anxiety sensitivity was the most important predictor of the anxiety for emerging adults. Further research examining the relationships between subdimensions of anxiety sensitivity and anxiety are necessary to strengthen the current study's findings.
\end{abstract}

Keywords Anxiety, Anxiety Sensitivity, Undergraduate Students, Structural Equation Modeling

\section{Introduction}

Anxiety is a condition which can be recognized by emotional reaction which may depend on personal feelings including tension, stress and nervousness [1]. Anxiety can be affected by both external and internal stimuli $[2,3]$.

It is proposed here that anxiety sensitivity is displayed differently by each individual difference and it may sometimes be characterized by the fear of anxiety-related feelings. These feelings result from anxiety-related beliefs. However, sometimes as a result of these feelings individuals may do themselves some harm [4]. There are some hypotheses over anxiety sensitivity and these hypothesis increase the levels of anxiety existing before it exists and acts as a risk cause. So anxiety disorders go up. Correlational $[5,6]$ and longitudinal [7] research has been done with both adults and adolescents, which showed that anxiety sensitivity is higher for men than for women. The same result has also been observed for anxiety disorders although it has firstly been imagined as a risk cause only for panic. By looking at these results, there is an agreement among the researchers that this pattern is related to some other anxiety disorders.

It is suggested that anxiety sensitivity is a composition of three intercorrelated lower-order components. These components supply with an overly large amount of a common higher-order factor. Furthermore, physical, psychological, and social concerns are usually mentioned for these three lower-order components. As a result, Cox, Borger, and Enns [5] and Moshier et al. [67] say that anxiety sensitivity plays an important role in anxiety.

There are a lot of theories proposed connected to anxiety sensitivity. Among these theories, anxiety sensitivity is said to serve a premorbid risk factor for the development of anxiety pathology in the expectancy theory [4]. It is also mentioned that the development and the severity of a lot of fears and anxiety conditions are affected by three fundamental fears in the expectancy theory $[4,8]$. According to expectancy theory, anxiety sensitivity is a genetically based aversion to anxiety that is combined with beliefs about the unwanted outcomes of anxiety [9]. When people who have high anxiety sensitivity level get anxious, they may explain or understand the symptoms caused by the anxiety incorrectly, and they might believe these symptoms will have harmful results so this has the potential to starts a cycle of anxiety behaviors [10,11, 12]. Namely, pure anxiety has another anxiety type, and this type of anxiety may finally change into a panic attack $[4,13]$. Individuals experiencing high anxiety sensitivity generally believe that they will experience some harmful feelings [14]. For example, these people may believe heart palpitations indicate a heart attack's coming while people with low anxiety sensitivity feel the same heart palpitations as bothersome. The parts of fear are worse for anxiety-sensitive people than for others [15].

There has been some important point of views of many cognitive and behavioral theories of anxiety such as the fear 
of anxiety more generally, an individual difference, and the concept of anxiety sensitivity [4, 17, 69]. Besides, some theoretical explanations have been proposed for the development of anxiety disorders [15]. For example, some people who experience high anxiety sensitivity may fear palpitations because they have some concerns about a heart attack or they fear sweating in public areas due to their own negative social evaluation. When we look at the anxiety sensitivity theory [4], people experiencing high anxiety sensitivity experience amplified fear at the time of stimuli that cause anxiety, and they draw conclusion that their anxiety symptoms are deterring by themselves [18].

Empirical studies have demonstrated that anxiety sensitivity is an important risk factor people with anxiety problems. Among these studies, firstly, it is signified that anxiety sensitivity presents as fear feelings which impact on the functioning of the senses $[19,20]$. Secondly, anxiety sensitivity levels are higher for people who have anxiety disorders [21]. Thirdly, in studies with healthy adults [22] and adolescents [23], they signify that even after anxiety sensitivity controls for trait anxiety, it has a prediction on the future occurrence of anxiety symptoms and panic attacks. It has also been understood in the research that there is a connection between anxiety sensitivity and the cognitive symptoms of anxiety [24, 25]. Koszycki and Bradwejn's study [46] shows that there is a relationship between the fear of cognitive dyscontrol subdimension of the anxiety sensitivity and panic-related disorders. Also, according to Yazıc1 [68] there is a relationship between the negative emotionality and anxiety sensitivity.

The relationship between anxiety sensitivity and various forms of anxiety-related psychopathology has been demonstrated in the research on anxiety sensitivity subdimensions [26]. Panic-related phenomena and the fear of bodily feelings are factors mostly associated with each other [27]. Anxiety sensitivity is raised in panic disorder as well as other anxiety disorders. It is thought to promote to the maintenance and severity of anxiety symptoms [28]. Also, the fear of cognitive dyscontrol factor and depression are reasonably connected to each other [27]. Social anxiety is mostly related to the social concerns factor $[29,30]$.

All of the above studies suggest that multidimensional assessment of anxiety sensitivity is valuable and supports the view that further research should focus on the relationships between anxiety sensitivity and anxiety-related variables. When the literature is examined, the importance of the current research shall be more explicitly seen considering the fact that neither a national nor an international research directly examining the relationship between anxiety sensitivity and anxiety was encountered. Hence, this study's main goal was to define whether anxiety sensitivity was related to anxiety. The current study's results are consideration to give significant information about the creation of anxiety in emerging adulthood period. Emerging adulthood contains to a period of development between adolescence and adulthood, generally including the 18-29 age range. Arnett [70] suggested emerging adulthood as a new life period at ages $18-29$, one distinct from both the adolescence that precedes it and the young adulthood that eventually follows. Arnett also emphasizes five distinguishing features of emerging adulthood: the age of identity explorations, the age of instability, the most self-focused age, the age of feeling in-between, and the age of possibilities.

\section{Materials and Methods}

\subsection{Model}

This is a quantitative and relational study aimed at examining the relationship between subdimensions of anxiety sensitivity and anxiety. Therefore, Pearson product-moment correlation analysis was used to explain for relationships between anxiety sensitivity and anxiety; structural equation modeling was employed for elucidating anxiety. The data were gathered by Anxiety Sensitivity Index-Revised, (ASI-R) [31], and Beck Anxiety Inventory, (BAI) [32].

\subsection{Participants}

Since this study was carried out on teacher candidates -prospective teachers-, the data were collected by randomly selected undergraduate students studying in department of physical education and sports teaching of School of Physical Education and Sports and different departments of the Faculties of Technical Education and Education at Mugla Sitk1 Kocman University. The study was designed in survey study model and 880 undergraduate students from different departments constituted the sample group of the study which was determined by simple random sampling of probability sampling method. The participants were 880 undergraduate students who took part in the study voluntarily and informed consent was obtained for all participants. Instruments used in the context of this research were applied to 880 participants. Prior to analyzing the data, participants' responses on the instruments were reviewed. It was determined that 39 undergraduate students had left a significant number of scale items empty (at least 5\%) or demonstrated central tendency bias; thus, they were excluded from data the set. The data analyses were conducted on the responses of the remaining 841 participants, 411 females $(48.88 \%)$ and 430 males $(51.12 \%)$. They were in 20-27 (emerging adulthood period) age range and, average age was 23.86 with a standard deviation of 2.17. $25.6 \%$ of the participants were freshmen, $23.5 \%$ sophomores, $24.8 \%$ juniors, and $26.1 \%$ of them were seniors.

\subsection{Instruments}

Anxiety Sensitivity Index-Revised (ASI-R) A self-report questionnaire of 36 items, the ASI-R [31] measures the fear related to emotions of anxiety. The scale is an extended 
version of ASI [33], where the samples are subject to answer particular questions, evaluating their fear levels compared to normal anxiety reactions such as lack of concentration, increased heart rate, sweating, and blushing. The scores obtained by the addition of the aforementioned items range between 0 to 144. Studies of Deacon, Abramowitz, Woods, and Tolin [34] conducted in two college samples revealed that there was an excellent internal consistency for the ASR-I $(.95 ; .94)$, whereas Kim et al. [35] found that the reliability (test-retest) (.82) was for a 3-week period. Çakmak [36] adapted the ASI-R in Turkey and demonstrated that the excellent internal consistency (.93) and the reliability (test-retest) (.83). In current study, Cronbach's alpha coefficients of subscales were found to be as follows: fear of cardiovascular symptoms .82, fear of respiratory symptoms .84, fear of publicly observable anxiety reactions .85 , and fear of cognitive dyscontrol .89 .

Beck Anxiety Inventory (BAI) The BAI [32] involves a self-report survey evaluated by a Likert scale comprising 21 items which measures the common clinical anxiety symptoms such as nervousness and fear of losing control. The samples' level of discomfort corresponds to a symptom and rated on a 4 point scale ranging from 0 (not at all) to 3 (severely, I could barely stand it). In the inventory, total scores range from 0 to 63 and the levels of anxiety are directly proportional with the higher scores. 13 of the 21 symptoms evaluate psychological symptoms, 5 of them evaluate cognitive aspects and 3 symptoms assess both somatic and cognitive symptoms. The internal inconsistency was quite high (alpha $=.92)$, and the concurrent validity with the SCL-90-R [45] anxiety subscale $\mathrm{r}=.81$ : Steer, Ranieri, Beck, and Clark [37] was quite satisfactory, and the inventory also demonstrated an average concurrent validity with the Hamilton Anxiety Rating Scale [38] in 367 outpatients with anxiety disorders $r=.56$ : Beck and Steer [39]. Ulusoy, Şahin, and Erkmen [40] adapted the inventory in Turkey and found that the internal consistency coefficient as .93. The Cronbach's alpha for the inventory was found .89 in the current study.

\subsection{Procedures}

A permit to collect data was acquired from the administration of Faculties of Technical Education, Education, and Sport Sciences at Mugla Sitk1 Kocman University, and significant data was obtained from where the classes and divisions were randomly selected by the researcher. While collecting the data, the undergraduate students were provided with the convenient time and proper environment to answer the questions as groups in a classroom.

\subsection{Data Analysis}

In this study, the model was created by testing the relationships between the anxiety sensitivity and anxiety variables using Structural equation modeling (SEM). While conducting the statistical analysis of the data, SPSS 17.00 and LISREL 8.70 were used. Accordingly, Pearson product-moment correlation analysis and structural equation modeling were used for analysing the correlation between anxiety sensitivity and anxiety. SEM, uses the combination of statistical data and qualitative casual assumptions to test and estimate casual relations. The aforementioned model was tested in terms of how well it fit the data, and was found that the casual assumptions included in the model had falsifiable results which in turn could be tested towards the data itself. SEM's strengths are its ability to construct latent variables which are not measured directly; rather estimated from several measurable variables that are assumed to "tap into" the latent variables. According to Grimm and Yarnold [41], Kline [42], and Sümer [43] this is a strength since it provides the modeler with the opportunity to find out the unreliability of a measurement and accordingly, enables the modeler to estimate accurately the structural correlation between latent variables [44].

\section{Results}

According to the results of this research there is a significant relationship between anxiety and subdimensions of anxiety sensitivity, and subdimensions of anxiety sensitivity important predictors of anxiety for prospective teachers.

\subsection{The Relationship between Anxiety and Subdimensions of anxiety sensitivity}

The relationship between anxiety and subdimensions of anxiety sensitivity was tested by using Pearson product-moment correlation analysis and results are presented in Table 1.

Table 1. The Correlations between Anxiety and Subdimensions of Anxiety Sensitivity

\begin{tabular}{|c|c|c|c|c|}
\hline & FRS & FPOAR & FCS & FCD \\
\hline Anxiety & $.44 * *$ & $.47 * *$ & $.42 * *$ & $.49 * *$ \\
\hline
\end{tabular}

$* \mathrm{p}<.01$ (FRS Fear of Respiratory Symptoms, FPOAR, Fear of Publicly Observable Anxiety Reactions, FCS Fear of Cardiovascular Symptoms, FCD Fear of Cognitive Dyscontrol)

Table 1 shows that anxiety is positively related to fear of respiratory symptoms, fear of publicly observable anxiety reactions, fear of cardiovascular symptoms, and fear of cognitive dyscontrol subdimensions of anxiety sensitivity.

\subsection{The Prediction of Anxiety by Subdimensions of Anxiety Sensitivity}

Structural equation modeling was performed to predict anxiety by subdimensions of anxiety sensitivity and the results are given in Figure 1. Figure 1 illustrates the developed structural model (standardized coefficients). 


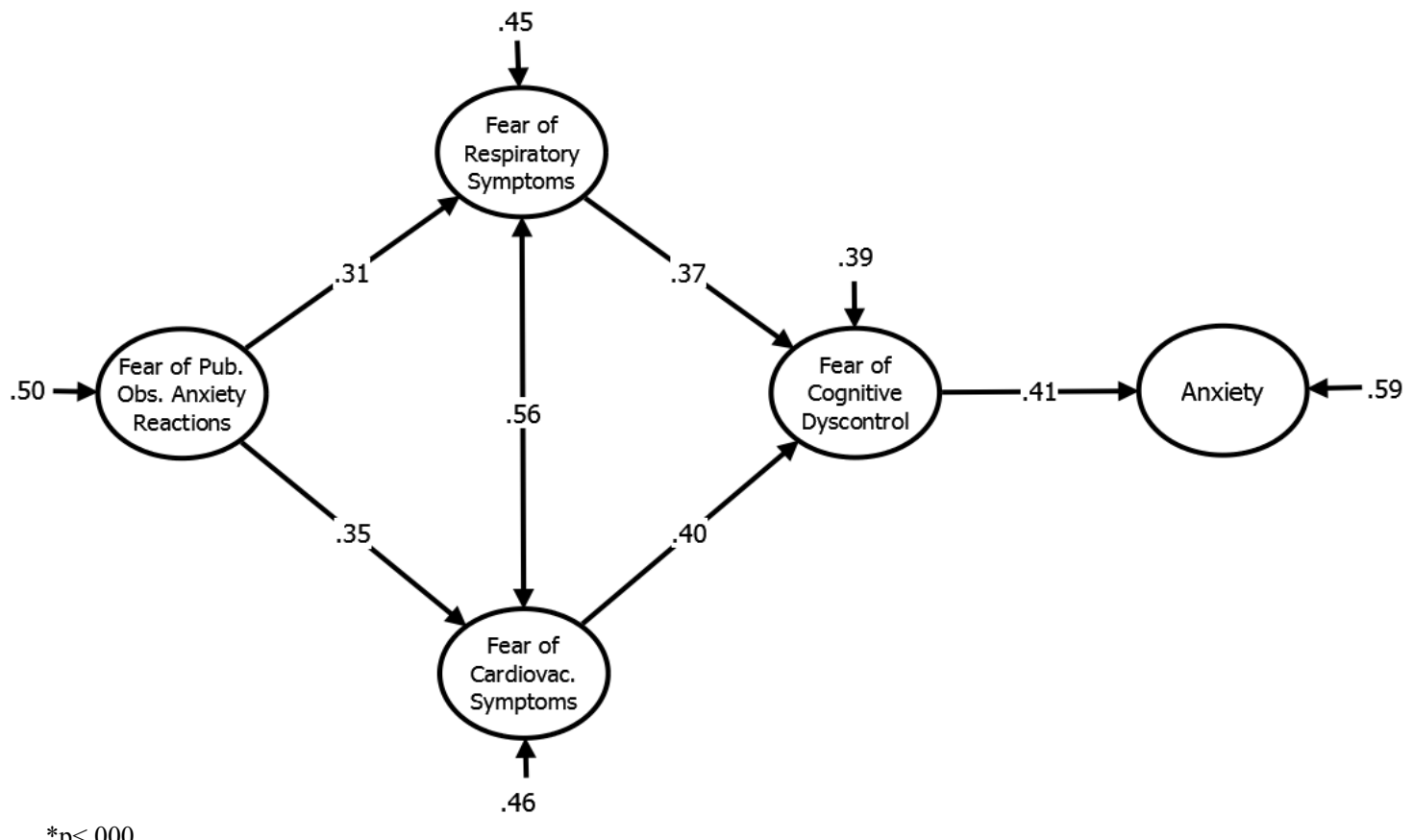

Figure 1. Path Diagram of Significant Predictors of Anxiety (Developed Structural Model)

The total points of subdimensions of anxiety sensitivity predict the anxiety between .31 and .59 . As can be seen in Figure 1, the data obtained fit well model. The fitness coefficients related to the developed structural model are above the acceptable limits. For example, the value of $\mathrm{NFI}=.93, \mathrm{NNFI}=.95, \mathrm{IFI}=.96, \mathrm{CFI}=.97, \mathrm{GFI}=.92, \mathrm{AGFI}=.88$, $\mathrm{RMR}=.07 ; \mathrm{SRMR}=.06, \mathrm{RMSEA}=.05, \chi 2=789.89, \mathrm{df}=275$, and $\chi 2 / \mathrm{df}=2.87$. These values indicate that the model is acceptable [42]. Standardized path coefficients were used to explain the effect of the independent variables -subdimensions of anxiety sensitivity- on anxiety. In this study, path coefficients ranged from .31 and .59 that is, all of the values were higher than .30. According to Kline [42], path coefficients with values around .30 could suggest a "typical effect", and values $\geq .50$ a "large effect".

\section{Discussion}

The results of this study support the view that all subdimensions of anxiety sensitivity are important factors that affect the anxiety level of late adolescents. The results also indicated that the fear of cognitive dyscontrol subdimension of anxiety sensitivity was the most important predictor of the anxiety for late adolescents.

In addition, the fear of openly recognizable anxiety responses subdimension of anxiety sensitivity is a prediction for anxiety. This result shows that the fear that is being openly scorned or criticised for reflecting anxiety symptoms is related to stimulation, and likewise fear, in the adolescent population. These social situations are known to start the panic attacks, and afterwards, are connected to full of fear avoidance behavior [15, 17]. The fear of breathing indications subdimension was discovered to have a relationship for late adolescents. It appeared that the extent to which anxiety symptoms experienced by late adolescents was related to a fear of respiratory indications [46]. Eventually, an important relationship was discovered between the fear of cardiovascular symptoms subdimension and anxiety for the late adolescent population. It appeared to be coherent with research having used biological challenges $[47,48]$, and emphasized this subdimension as an important predictor of fear reactions.

Anxiety sensitivity is thought as an obligatory cause for the nursing and development of anxiety disorders [8]. It can be said that there is much changeability in experiencing anxiety. While some people can easily feel stressful when they are provoked less, the others need more stressful situations to feel the same feeling. Trait anxiety is related to personal differences [49]. Namely, people experience anxiety in different ways [50]. There is a wide definition of trait anxiety and we can understand it by looking at however much tendency to become anxious individuals have and how it is seen as dangerous feeling [51]. Anxiety sensitivity is a significant factor for development and manifestation of anxiety disorders [18]. Troubling beliefs or thoughts after some negative events include the fear of anxiety, and so anxiety sensitivity appears $[50,52]$. People can feel the sensation of fear because of the possible physical, psychological, or social consequences. When college students experience a social interaction, it has been discovered that anxiety sensitivity is a prediction for anxious reactions [53]. Reiss and McNally [8] have formed a hypothesis that anxiety sensitivity is obligatory for the nursing and development of anxiety disorders.

Physical, mental, and publicly observable experience fear of types are included in anxiety sensitivity [30]. All of these fears have a potential of increasing preexisting anxiety [4]. A 
person's fear of becoming insane or losing control was associated with the experience of a lot of anxiety symptoms. This study is coherent with prior research, and anxious patients misunderstand their anxiety symptoms in this research. They feel this sensation is a disorder of mental disturbance [5, 46, 54]. Deacon and Abramowitz [55] say that the fear of cognitive dyscontrol subdimension is associated with anxiety disorders strongly. These anxiety disorders can contain obsessive-compulsive disorder in addition to generalised anxiety disorder, and panic disorder. Clark [17] said that the role of the fear of cognitive dyscontrol can be misunderstood as an indicator of loose one's senses.

There is variability not only in the inclination for experiencing anxiety, but also in the fear of experiencing anxiety symptoms of individuals. The individual differences related to the fear of anxiety are represented by the construct of anxiety sensitivity [8]. Anxiety sensitivity is a firm and trait like characteristic of pre-dispositional construct. This construct indicates that the fear of anxiety can be associated with troubling thoughts or beliefs of symptoms after the individuals experience some negative consequences of the feelings [50, 52]. For instance, while a person who has high anxiety sensitivity level feels that he or she is having a big problem such as a heart attack, another person who has low anxiety sensitivity level just feels and thinks that there is an uncomfortable and unpleasant situation [50]. Other people also can fear these feelings because of the concerns of their social evaluation, as well as fearing anxiety based on a misunderstanding of impending physical or mental complications [56].

The significant role of anxiety sensitivity in anxiety pathology becomes apparent by comparing anxiety sensitivity scores between persons with different clinical symptom or between patients with versus without symptom [57]. Wheaton, Deacon, McGrath, Berman, and Abramowitz [58] observed that physical, social, and cognitive concerns subscale scores of patients with any anxiety disorder had significantly higher scores than controls. Allan, Capron, Raines, and Schmidt [24] and Olthuis, Watt, and Stewart [59] found that the anxiety disorder group confirmed more serious physical and cognitive concerns than the other groups.

The global anxiety sensitivity factor interceded the connection between the development of anxiety symptoms and stress, in addition to concerns about mental incapacitation and disease. Among children and adolescents, the uncontrollable stressful things in life have been involved in the pathogenesis of anxiety symptomatology [60]. Accumulating evidence showed that the anxiety symptoms were associated with anxiety sensitivity in children and adolescents $[18,61]$. The development of psychopathology characterizes the adolescence period in a higher risk rate Essau, Sasagawa, and Ollendick, [62] than the other topics in development. Also, troubling situations are more connected to the appearance of negative effect during the adolescence stage. Adolescents become more unprotected to the effects of strain in an emotional manner [63].

It was observed that there were individual differences in anxiety sensitivity, which were thought to derive from a combination of influences of genetic variation and certain previous experiences which cause a conventional belief regarding the potentially aversive outcomes of arousal and anxiety-related states $[9,64]$. The Anxiety Sensitivity Index was administered to nearly 50 college students by Maller and Reiss [7], and the students were followed in the future for evaluation of future diagnostic status. According to the findings, the students who had high Anxiety Sensitivity Index scores had five times greater risk for developing an anxiety disorder than another group with low baseline Anxiety Sensitivity Index scores in the three-year period.

People who believe that anxiety symptoms point out negative social and physical results are considered to be more unprotected to the development of anxiety pathology. People who have high anxiety sensitivity are more possible to behave in different ways related to anxiety, such as increased heart rate or sweating, and they misunderstand these symptoms as harmful and terrible. These explanations of bodily feelings may cause more anxiety and can cause to continue a vicious cycle by increasing. Finally, this process cause to avoidance, panic attacks, or raised anxiety symptoms $[4,7]$. People who have a high level of anxiety sensitivity suffer more from, for example, heart attacks after a fear with heart palpitations than the others who have a low level of anxiety sensitivity. Because they believe that these feelings are temporary and comparatively not harmful. Barlow, Chorpita, and Turovsky [16] said that anxiety sensitivity increases anxiety reactions. Because the awareness of anxiety symptoms causes to enhanced anxiety associated with harmful results. And this vicious cycle continues by increasing the anxiety symptoms. For example, Broman-Fulks, Urbaniak, Bondy, and Toomey [65] and Kurdziel, Collado-Rodriguez, Townsend, MacPherson, and Lejuez [66] found that individuals with high anxiety sensitivity reported engaging in significantly fewer risk-taking behaviors than those with low anxiety sensitivity.

\section{Conclusions}

In this study, it was found that there was a positive relationship between subdimensions of anxiety sensitivity and anxiety. Fear of respiratory symptoms, fear of publicly observable anxiety reactions, fear of cardiovascular symptoms, and fear of cognitive dyscontrol subdimensions of anxiety sensitivity were associated with anxiety in emerging adults. This study also revealed that Fear of respiratory symptoms, fear of publicly observable anxiety reactions, fear of cardiovascular symptoms, and fear of cognitive dyscontrol subdimensions of anxiety sensitivity significantly explains anxiety.

As a result of the current study, it can be said that anxiety sensitivity is an important risk factor to identify in emerging adults with anxiety. It should be noted that within this 
context, subdimensions of anxiety sensitivity are closely connected with many biopsychosocial problems such as several anxiety disorders, panic attacks, maladaptive perfectionist tendencies, negative emotionality, avoidance behaviors, and depressive tendencies.

\section{Limitations}

There are certain limitations with regards to the assessment of the applicability of the results obtained from this study. First limitation is that this study solely comprised graduate students in the department of education, which means that this study may not reflect the varying experiences and requirements of students in other departments. Furthermore, the graduate students in the department of education may not have been represented wholly, since the sample size was small. The second limitation which may be encountered in the study derives from the self-report feature of the instruments used. Since the aforementioned instruments solely relied on the individual perceptions of participants, inaccurate or falsified self-reports may significantly influence the accuracy of the study. The fact that participants generally aimed to provide socially "correct" answers rather than "honest" ones may influence the reliability of the self-report aspect of the study. To sum up; in addition to anxiety sensitivity, other aspects such as cognitive, physiological, and personality factors may have an influence on the study. For this reason, further researches may be required in order to identify the aforementioned factors and the extent of their influence on anxiety sensitivity and experiences.

\section{Recommendations}

In spite of these limitations, the study may be considered successful due to having revealed important correlations between the subdimensions of anxiety sensitivity and anxiety and having improved the previous research. It may also be asserted that it provided significant information related to the subject, of which the results would provide significant data on the formation of anxiety in emerging adulthood period. Hence, these results may shed a light to future researches and intervention strategies on revealing the particularly important aspects of anxiety sensitivity.

The behavioral problems in the emerging adulthood period should be accurately prevented. Within this context, preventive counseling services should comprise the education of healthy ways for managing the problems in the emerging adulthood period, which are considered to be useful for the individuals, parents, and educators.

\section{Acknowledgements}

We are very grateful to experts for their appropriate and constructive suggestions to improve this template.

\section{REFERENCES}

[1] Tovote, P., Fadok, J.P., \& Lüthi, A. (2015). Neuronal circuits for fear and anxiety. Nature Reviews Neuroscience, 16, 317-331.

[2] Chesler, M.A., Allswede, J., \& Barbarin, O.O. (1991). Voices from the margin of the family: siblings of children with cancer. Journal of Psychosocial Oncology, 9, 19-42.

[3] Adams-Greenly, M., Shiminski-Maher, T., McGowan, N. \& Meyers, P.A. (1986) A group program for helping siblings of children with cancer. Journal of Psychosocial Oncology, 4, 55-67.

[4] Reiss, S. (1991). The expectancy model of fear, anxiety, and panic. Clinic Psychology Review, 11, 141-153.

[5] Cox, B.J., Borger, S.C., \& Enns, M.W. (1999). Anxiety sensitivity and emotional disorders: psychometric studies and their theoretical implications. In S. Taylor (Ed.), Anxiety sensitivity: theory, research, and treatment of the fear of anxiety (pp. 115-148). Mahwah, NJ: Lawrence Erlbaum Associates.

[6] Rabian, B., Peterson, R.A., Richters, J., \& Jensen, P.S. (1993). Anxiety sensitivity among anxious children. Journal of Clinical Child Psychology, 22, 441-446.

[7] Maller, R.G., \& Reiss, S. (1992). Anxiety sensitivity in 1984 and panic attacks in 1987. Journal of Anxiety Disorders, 6, 241-247.

[8] Reis, S., \& McNally, R.J. (1985). The expectancy model of fear. In: Reiss, S. \& Bootzin, R.R., Editors. Theoretical issues in Behavior Therapy. New York: Academic Press.

[9] Reiss, S., \& Havercamp. S.M. (1996). The sensitivity theory of motivation: implications for psychopathology. Behaviour Research and Therapy, 34, 621-632.

[10] Broman-Fulks, J.J., Urbaniak, A., Bondy, C.L., \& Toomey, K.J. (2014). Anxiety sensitivity and risk-taking behavior. Anxiety Stress Coping, 27, 619-632.

[11] Naragon-Gainey, K. (2010). Meta-analysis of the relations of anxiety sensitivity to the depression and anxiety disorders. Psychological Bulletin, 136, 128-150.

[12] Worden, B.L., Davis, E., Genova, M., \& Tolin, D.F. (2015). Development of an anxiety sensitivity (as) intervention for high-as individuals in substance use disorders treatment. Cognitive Therapy and Research, 39, 343-355.

[13] Carter, M.M., Miller, O., Sbrocco, T., Suchday, S., \& Lewis, E.L. (1999). Factor structure of the Anxiety Sensitivity Index among African American college students. Psychological Assessment, 11, 525-533.

[14] Steinman, S.A., \& Teachman, B.A. (2010). Modifying interpretations among individuals high in anxiety sensitivity. Journal of Anxiety Disorders, 24, 71-78.

[15] McNally, R.J. (1994). Panic disorder: a critical analysis. New York: Guilford Press.

[16] Barlow, D.H., Chorpita, B.F., \& Turovsky, J. (1996). Fear, panic, anxiety, and the disorders of emotion. In D. A. Hope (Ed.), Nebraska symposium on motivation: perspectives on anxiety, panic, and fear (Vol. 43, pp. 251-328). Lincoln: University of Nebraska Press. 
[17] Clark, D.M. (1986). A cognitive approach to panic. Behaviour Research and Therapy, 24, 461-470.

[18] Stevanovic, D. (2013). Anxiety sensitivity in relation to anxiety symptoms among Serbian youth. International Journal of Clinical Psychiatry and Mental Health, 1, 25-32.

[19] Rabian, B., Embry, L., \& MacIntyre, D. (1999). Behavioral validation of the Childhood Anxiety Sensitivity Index in children. Journal of Clinical Child Psychology, 28, 105-112.

[20] Zvolensky, M.J., McNeil, D.W., Porter, C.A., \& Stewart, S.H. (2001). Assessment of anxiety sensitivity in young American Indians and Alaska Natives. Behaviour Research and Therapy, 39, 477-493.

[21] Kearney, C.A., Albano, A.M., Eisen, A.R., Allan, W.D., \& Barlow, D.H. (1997). The phenomenology of panic disorder in youngsters: an empirical study of a clinical sample. Journal of Anxiety Disorders, 11, 49-62.

[22] Schmidt, N.B., Lerew, D.R., \& Jackson, R.J. (1999). Prospective evaluation of anxiety sensitivity in the pathogenesis of panic: replication and extension. Journal of Abnormal Psychology, 108, 532-537.

[23] Hayward, C., Killen, J.D., Kraemer, H.C., \& Taylor, C.B. (2000). Predictors of panic attacks in adolescents. Journal of the American Academy of Child and Adolescent Psychiatry, 39, 207-214.

[24] Allan, N.P., Capron, D.W., Raines, A.M., \& Schmidt, N.B. (2014). Unique relations among anxiety sensitivity factors and anxiety, depression, and suicidal ideation. Journal of Anxiety Disorders, 28, 266-275.

[25] Clerkin, E.M., Beard, C., Fisher, C.R., \& Schofield, C.A. (2015). An attempt to target anxiety sensitivity via Cognitive Bias Modification. PLoS One, 10, 1-13.

[26] MacDonald, E.M., Koerner, N., \& Antony, M.M. (2013). Modification of interpretive bias: impact on anxiety sensitivity, information processing and response to induced bodily sensations. Cognitive Therapy and Research, 37, 860-871.

[27] Taylor, S., Koch, W.J., Woody, S., \& McLean, P. (1996) Anxiety sensitivity and depression: how are they related? Journal of Abnormal Psychology, 105, 474-479.

[28] Mantar, A., Yemez, B., \& Alkın, T. (2011). Anxiety sensitivity and its importance in psychiatric disorders. Turkish Journal of Psychiatry, 22, 187-193.

[29] McWilliams, L.A., Stewart, S.H., \& MacPherson, P.S.R. (2000). Does the social concerns component of the Anxiety Sensitivity Index belong to the domain of anxiety sensitivity or negative evaluation sensitivity? Behaviour Research and Therapy, 38, 985-992.

[30] Zinbarg, R.E., \& Barlow, D.H. (1996). The structure of anxiety and the anxiety disorders: a hierarchical model. Journal of Abnormal Psychology, 105, 181-193.

[31] Taylor, S., \& Cox, B.J. (1998). An expanded anxiety sensitivity index: evidence for a hierarchic structure in a clinical sample. Journal of Anxiety Disorders, 12, 463-483.

[32] Beck, A.T., Epstein, N., Brown, G., \& Steer, R.A. (1988). An inventory for measuring clinical anxiety: psychometric properties. Journal of Consulting and Clinical psychology, 56, 893-897.
[33] Reiss, S., Peterson, R.P., Gursky, D.M., \& McNally, R.J. (1986). Anxiety sensitivity, anxiety frequency, and the prediction of fearfulness. Behaviour Research and Therapy, $24,1-8$.

[34] Deacon, B.J., Abramowitz, J.S., Woods, C.M., \& Tolin, D.F. (2003). The Anxiety Sensitivity Index-Revised: psychometric properties and factor structure in a nonclinical sample. Behaviour Research and Therapy, 41, 1427-1449.

[35] Kim, J.H., Yu, B.H., Oh, K.S., Yang, J.C., Kim, Y., Lee, S.Y., \& Lim, Y.J. (2004). A validation study of Korean Anxiety Sensitivity Index-Revised (ASI-R). Journal of Korean Neuropsychiatry Association, 43, 54-61.

[36] Çakmak, S.S. (2006). Psychometric properties of anxiety sensitivity index-revised and the relationship with drinking motives and alcohol use in Turkish university students and patients. Unpublished Master Thesis, Graduate School of Social Sciences, Middle East Technical University, Ankara.

[37] Steer, R.A., Ranieri, W.F., Beck, A.T., \& Clark, D.A. (1993). Further evidence for the validity of the Beck Anxiety Inventory with psychiatric outpatients. Journal of Anxiety Disorders, 7, 195-205.

[38] Hamilton, M. (1959). The assessment of anxiety states by rating. British Journal of Medical Psychology, 32, 50-55.

[39] Beck, A.T., \& Steer, R.A. (1991). Relationship between the Beck Anxiety Inventory and the Hamilton Anxiety Rating Scale with anxious outpatients. Journal of Anxiety Disorders, 5, 213-223.

[40] Ulusoy, M., Şahin, N., \& Erkmen, H. (1998). Turkish version of the Beck Anxiety Inventory: psychometric properties. Journal of Cognitive Psychotherapy: An International Quarterly, 12, 74-81.

[41] Grimm, L. G., \& Yarnold, P. R. (2000). Reading and understanding more multivariate statistics. Washington, DC: American Psychological Association.

[42] Kline, R.B. (2005). Principle and practice of structural equation modeling, (2nd Ed.). New York: Guilford Press.

[43] Sümer, N. (2000). Structural equation modeling: basic concepts and sample practices. Turkish Psychological Manuscripts, 3, 49-74.

[44] Erözkan, A. (2013). Assessment of social problem solving with respect to emotional intelligence. The Online Journal of Counselling and Education, 2, 16-32.

[45] Derogatis, L.R. (1983). SCL-90-R administration, scoring, and procedures manual-II. Clinical Psychometric Research, Towson, MD.

[46] Koszycki, D., \& Bradwejn, J. (2001). Anxiety sensitivity does not predict fearful responding to $35 \%$ carbon dioxide in patients with panic disorder. Psychiatry Research, 101, 137-143.

[47] Brown, M., Smits, J.A.J., Powers, M.B., \& Telch, M.J. (2003). Differential sensitivity of the three ASI factors in predicting panic disorder patients' subjective and behavioural response to hyperventilation challenge. Journal of Anxiety Disorders, $17,583-591$

[48] Rapee, R.M., \& Medoro, L. (1994). Fear of physical sensations and trait anxiety as mediators of the response to hyperventilation in non-clinical subjects. Journal of 
Abnormal Psychology, 103, 693-699.

[49] Mărcuş, O., Stanciu, O., MacLeod, C., Liebregts, H., \& Visu-Petra, L. (2015). A FISTful of emotion: individual differences in trait anxiety and cognitive-affective flexibility during preadolescence. Journal of Abnormal Child Psychology, 22, 1-12.

[50] Taylor, S. (1999). Anxiety sensitivity: theory, research, and treatment of the fear of anxiety. New Jersey: Erlbaum.

[51] Beck, A.T., \& Emery, G. (1985). Anxiety disorders and phobias: A cognitive perspective. New York: Basic Books.

[52] Scott, E. L., Heimberg, R. G., \& Jack, M. S. (2000). Anxiety sensitivity in social phobia: Comparison between social phobics with and without panic attacks. Depression and Anxiety, 12, 189-192.

[53] Gore, K.L., Carter, M.M., \& Parker, S. (2002). Predicting anxious response to a social challenge: the predictive utility of the social interaction anxiety scale and the social phobia scale in a college population. Behaviour Research and Therapy, 40, 689-700.

[54] Zinbarg, R.E., Mohlman, J., \& Hong, N.N. (1999). Dimensions of anxiety sensitivity. In S. Taylor (Ed.), Anxiety sensitivity: theory, research, and treatment of the fear of anxiety (pp. 3-17). New Jersey: Lawrence Erlbaum Associates.

[55] Deacon, B., \& Abramowitz, J. (2006). Anxiety sensitivity and its dimensions across the anxiety disorders. Journal of Anxiety Disorders, 20, 837-857.

[56] Olatunji, B.O., \& Wolitzky-Taylor, K.B. (2009). Anxiety sensitivity and the anxiety disorders: a meta-analytic review and synthesis. Psychological Bulletin, 135, 974-999.

[57] Kemper, C.J., Lutz, J., Bähr, T., Rüddel, H. \& Hock, M. (2012). Construct validity of the Anxiety Sensitivity Index-3 in clinical samples. Assessment, 19, 89-100.

[58] Wheaton, M.G., Deacon, B. J., Mcgrath, P.B., Berman, N.C., \& Abramowitz, J.S. (2012). Dimensions of anxiety sensitivity in the anxiety disorders: evaluation of the ASI-3. Journal of Anxiety Disorders, 26, 401-408.

[59] Olthuis, J.V., Watt, M.C., \& Stewart, S.H. (2014). Anxiety Sensitivity Index (ASI-3) subscales predict unique variance in anxiety and depressive symptoms. Journal of Anxiety Disorders, 28, 115-124.
[60] Grant, K.E., Compas, B.E., Thurm, A.E., McMahon, S.D., \& Gipson, P.Y. (2004). Stressors and child and adolescent psychopathology: measurement issues and prospective effects. Journal of Clinical Child and Adolescent Psychology, $33,412-425$.

[61] Stevanovic, D., Silverman, W.K., Nichols-Lopez, K., Popovic-Deusic, S., \& Pejovic-Milovancevic, M. (2013). Facets of the childhood anxiety sensitivity index among Serbian youth. Cognitive Behaviour Therapy, 42, 342-346.

[62] Essau, C.A., Sasagawa, S., \& Ollendick, T.H. (2010). The facets of anxiety sensitivity in adolescents. Journal of Anxiety Disorders, 24, 23-29.

[63] Larson, R.W., Moneta, G., Richards, M.H., \& Wilson, S. (2002). Continuity, stability, and change in daily emotional experience across adolescence. Child Development, 73, 1151-1165.

[64] Bardeen, J.R., Fergus, T.A., \& Orcutt, H.K. (2013). Experiential avoidance as a moderator of the relationship between anxiety sensitivity and perceived stress. Behavior Therapy, 44, 459-469.

[65] Broman-Fulks, J. J., Urbaniak, A., Bondy, C. L., \& Toomey, K. J. (2014). Anxiety sensitivity and risk-taking behavior. Anxiety Stress Coping, 27, 619-632.

[66] Kurdziel, G.. Collado-Rodriguez, A., Townsend, J.M., MacPherson, L., \& Lejuez, C.W. (2014). Differences in anxiety sensitivity and sensation-seeking in relation to risk-taking on the Balloon Analogue Risk Task (BART). Drug and Alcohol Dependence, 140, 113-126.

[67] Moshier, S.J., Hearon, B.A., Calkins, A.W., Szuhany, K.L., Utschig, A.C., et al. (2013). Clarifying the link between distress intolerance and exercise: elevated anxiety sensitivity predicts less vigorous exercise. Cognitive Therapy and Research, 37, 476-482.

[68] Yazıc1, H. (2013). Relationships between anxiety sensitivity of academics and some variables such as gender, age, and personality. The New Educational Review, 34, 20-29.

[69] Barlow, D.H. (2001). Anxiety and its disorders: the nature and treatment of anxiety and panic (second edition). New York: Guilford Press.

[70] Arnett, J.J. (2015). The Oxford handbook of emerging adulthood. New York, NY: Oxford University Press. 